\title{
A vision for a more trans-inclusive publishing world
}

\section{NATALYA EVANS}

\author{
University of Southern California
}

Presenting Author: n.evans@usc.edu

Transgender, non-binary, and other gender diverse scientists and students face disproportionate barriers within the geosciences in class, lab, and field work. The retention of names linked to pre-transition identities acts as such a barrier because many people experience a unique form of trauma linked to their pre-transition identities. The emphasis on name recognition within academic communities exacerbates this issue. Equitable name change policies contain five guiding principles: name changes should be accessible and available without unnecessary barriers such as legal documentation, they should remove all instances of an author's previous names maintained and disseminated by the publisher, they should not draw attention to the change in name by posting notes or revisions, they need to be implemented simply and quickly without bureaucratic challenges, and changed names should be audited and maintained to prevent the previous name from recurring.

Recent work by trans authors, most notably Tess Tanenbaum, Irving Rettig, H Michael Schwartz, BM Watson, Teddy G Goetz, Katta Spiel, and Mike Hill, has succeeded in updating discriminatory policies within various journals. As this group worked to revise Wiley's name change policy with editor Lisa Pecher, I pushed to propagate this name change to journals in the American Geophysical Union (AGU) and the Association for the Sciences of Limnology and Oceanography (ASLO). Publications in both these societies is housed in Wiley, but editorial decisions go through the societies, such that the editorial offices needed to revise their name change policies too. In this session, I will discuss my experiences advocating for a trans-inclusive name change policy in AGU, ASLO, and Elsevier, which have confirmed via personal communication that they will update their policy, but circa abstract submission have not publicly released this information. I will also elaborate on the guiding principles for an equitable name change policy and common sticking points with publishers. 